Romanenko I. Yu. Prognostic significance of some clinical psycho-physiological signs in women - IDPs with Threatened Interruption of Pregnancy, Living in Lugansk Region. Journal of Education, Health and Sport. 2020;10(11):292-297. eISSN 2391-8306. DOI http://dx.doi.org/10.12775/JEHS.2020.10.11.029

https://apcz.umk.pl/czasopisma/index.php/JEHS/article/view/JEHS.2020.10.11.029

https://zenodo.org/record/4520797

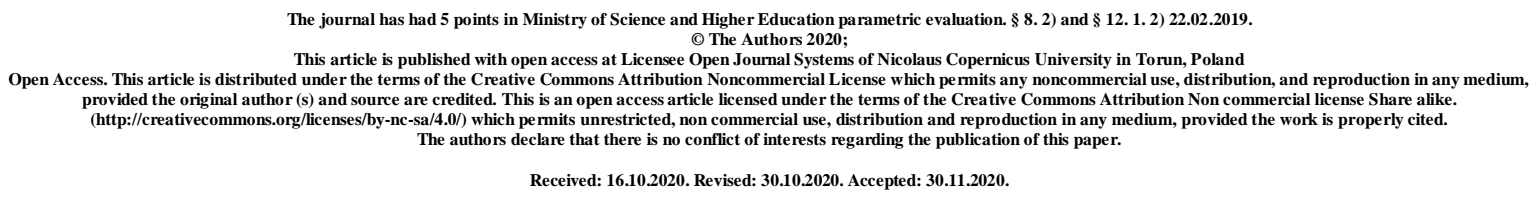

UDC 618.39-036.3/.4:616.89-008.19-07:[612.621.31:612.43.018]- 055.2"364"(477.61)

\title{
Prognostic significance of some clinical psycho-physiological signs in women - IDPs with Threatened Interruption of Pregnancy, Living in Lugansk Region
}

\author{
Romanenko I. Yu.
}

\section{Ukrainian Scientific and Practical Center for Endocrine Surgery, Transplantation of Endocrine Organs and Tissues of the Ministry of Health of Ukraine, Kyiv, Ukraine}

\begin{abstract}
The threatened interruption of pregnancy (TIP) is the most common pregnancy complication that occurs in $15-20 \%$ of cases of ongoing pregnancy. Chronic stress can affect the course of pregnancy, leading to an increase in the number of complications. The aim of the study was to develop a mathematical model for assessing the risk of premature birth in IDPs women with threatened interruption of pregnancy in the I and II trimesters, living in the Lugansk region in the area of armed conflict in Eastern Ukraine, to improve treatment and prophylactic measures and prevent obstetric and perinatal complications in such women. Material and methods. The study included 220 pregnant women in first and second trimesters of pregnancy who were hospitalized regarding threatened miscarriage in the hospitals, located in the Luhansk region, 47 women of which had IDPs status. The control group consisted of 30 pregnant women with non-complicated obstetric anamnesis and physiological course of pregnancy with similar gestational period of pregnancy and place of residence. The General clinical laboratory test, biochemical blood tests, coagulogram, colpocytology, $\mathrm{pH}$ determination and microscopic examination of the vaginal content,
\end{abstract}


concentrations of estradiol, progesterone, prolactin, cortisol, dehydroepiandrosterone sulfate, testosterone, thyroid stimulating hormone (TSH), serotonin, vitamin 25-(OH)D were carried out. Psychological research included the Beck's depression Inventory, Spielberger State-Trait Anxiety Inventory, The Pittsburgh Sleep Quality Index (PICS). The subjective severity of headache (tension-type headache (TTH) and migraine) was determined by visual analogue scale (VAS). Results and discussion. The following discriminant variables can be predictors of the risk of premature birth: a displacement factor, a presence of comorbidities, diseases of the urinary tract, bacterial vaginosis, indicators of Beck's depression Inventory, State and Trait anxiety, autonomic dystonia, PICS, concentrations of TSH, progesterone, DHEA-s, cortisol, serotonin, vitamin 25-(OH)D, an expressiveness of TTH by VAS. Conclusions. The developed mathematical model for assessing the risk of preterm birth in IDPs women has an informative value of $88.2 \%$ and can be used for primary screening. The above formula allows us to identify a group of patients who need further in-depth diagnostic search and indications for preventive measures.

\section{Keywords: pregnancy; threatened interruption of pregnancy; internally displaced persons; discriminant analysis.}

Background. By definition, Internally displaced persons (IDPs) are «Persons or groups of persons who have been forced or obliged to flee or to leave their homes or places of habitual residence, in particular as a result of or in order to avoid the effects of armed conflict, situations of generalized violence, violations of human rights or natural or human-made disasters, and who have not crossed an internationally recognized State border» [1]. As of the end of 2019, 50.8 million people were living in internal displacement because of conflict, violence and disasters [2].

The protracted armed conflicts create not only political, legal, socio-economic problems, form the migration flows of the population, but also affect the somatic and mental health of people. Women involved in armed conflict are often influenced by traumatic events and daily stresses with a risk of increased levels of mental disorders; Pregnancy itself is a critical stage in the development of a woman's personality. Chronic stress can affect the course of pregnancy, leading to an increase in the number of complications. During and after emergencies, people begin to face various mental health problems. Some of them have additional mental disorders, while others experience psychological distress $[3,4,5,6]$.

The threatened interruption of pregnancy (TIP) is the most common pregnancy complication that occurs in $15-20 \%$ of cases of ongoing pregnancy. TIP has associated with 
preterm labor and low birth weight, pre-eclampsia, preterm prelabour rupture of membranes, placental abruption and intrauterine growth restriction [7]. Despite successes in the study of etiology, pathogenesis, and the development of various methods for diagnosing and treating the threatened interruption of pregnancy, the frequency of miscarriages remains stable $[8,9$, $10]$.

Insufficient coverage of predicting the development of premature termination of pregnancy in women - IDPs with threatened miscarriage.

The aim of the study was to develop a mathematical model for assessing the risk of premature birth in IDPs women with threatened interruption of pregnancy in the I and II trimesters, living in the Lugansk region in the area of armed conflict in Eastern Ukraine, to improve treatment and prophylactic measures and prevent obstetric and perinatal complications in such women.

Material and Methods. The study included 220 pregnant women in first and second trimesters of pregnancy who were hospitalized regarding threatened miscarriage in the hospitals, located in the Luhansk region, 47 women of which had IDPs status. The control group consisted of 30 pregnant women with non-complicated obstetric anamnesis and physiological course of pregnancy with similar gestational period of pregnancy and place of residence. Before the start of the examination, each woman signed an Informed Consent of the patient to conduct diagnostics, treatment and processing of personal data. The studies were conducted in compliance with the basic bioethical norms and the requirements of the Helsinki Declaration. The criteria for inclusion in the main group were the woman's voluntary informed consent, the presence of symptoms of threatened abortion, I and II trimester of pregnancy.

Comprehensive clinical and obstetric examination in accordance to the current orders of the Ministry of Health of Ukraine was carried out. General clinical laboratory tests (blood group and $\mathrm{Rh}$ factor, general blood and urine tests), biochemical blood tests, coagulogram, colpocytology, $\mathrm{pH}$ determination and microscopic examination of the vaginal content), the concentrations of estradiol, progesterone, prolactin, cortisol, dehydroepiandrosterone sulfate (DHEA-s), testosterone, thyroid stimulating hormone, serotonin, vitamin 25-(OH)D were carried out. Psychological research included the Beck's depression Inventory, Spielberger State-Trait Anxiety Inventory (STAI), The Pittsburgh Sleep Quality Index (PICS). The subjective severity of headache (tension-type headache (TTH) and migraine) was determined by visual analogue scale (VAS). 
Statistical data processing was performed using SPSS 17.0 and Microsoft Excel for Windows (2013). Discriminant analysis was used to create prognostic models based on the results obtained during the survey.

Results and Discussion. The average age of women in group I was Me (Q1-Q3) = 26.00 (22.00-32.50), in group II - 25.50 (21.00-30.75), in group III - 24.50 (20.75-30.00) years. The largest number of patients was observed at the age of 20-30 years (31 (68.89\%), $131(74.86 \%)$ and $22(73.33 \%)$, respectively), that is, among the active and employable part of the population.

At the first stage, a clinical examination, history, blood hormone tests, psychological examination were performed.

In the second stage, according to clinical, psychological and laboratory examination, the functions of classification F1 and F2 are calculated according to the following formulas:

$\mathrm{F} 1=276,532+33,913 \times \mathrm{DF}-8,756 \times \mathrm{COM}-9,704 \times \mathrm{DUT}+3,736 \times \mathrm{BV}+2,388 \times$ Beck $+0,137 \times \mathrm{SA}+0,517 \times \mathrm{TA}+0,577 \times \mathrm{AD}+8,454 \times \mathrm{PICS}-3,048 \times \mathrm{TSH}+0,157 \times \mathrm{P}+$ 2,498 $\times$ DHEA-s $+0,004 \times \mathrm{K}-0,015 \times \mathrm{S}-2,955 \times \mathrm{D}-2,266 \times \mathrm{VAS}$ TTH

$\mathrm{F} 2=290,964+30,613 \times \mathrm{DF}+12,425 \times \mathrm{COM}-11,689 \times \mathrm{DUT}+2,193 \times \mathrm{BV}+2,841 \times$ Beck $+0,174 \times \mathrm{SA}+0,333 \times \mathrm{TA}+0,513 \times \mathrm{AD}+8,656 \times \mathrm{PICS}-4,057 \times \mathrm{TSH}+0,096 \times \mathrm{P}+$ $1,036 \times$ DHEA-s $-0,014 \times \mathrm{K}-0,011 \times \mathrm{S}-1,770 \times \mathrm{D}-2,637 \times \mathrm{VAS}$ TTH,

where DF is a displacement factor;

COM - presence of comorbidities;

DUT - presence of diseases of the urinary tract;

BV - presence of bacterial vaginosis;

Beck - indicator of Beck's depression Inventory;

SA - indicator of State anxiety;

TA - indicator of Trait anxiety;

$\mathrm{AD}$ - indicator of autonomic dystonia;

PICS - indicators of The Pittsburgh Sleep Quality Index;

TSH - concentration of thyroid stimulating hormone;

$\mathrm{P}$ - concentration of progesterone;

DHEA-s - concentration of DHEA-s;

$\mathrm{K}$ - concentration of cortisol;

$\mathrm{S}$ - concentration of serotonin; 
D - concentration of vitamin 25-(OH)D;

VAS TTH - the expressiveness of TTH by VAS.

In the third stage, F1 and F2 are compared. If after the calculations F2> F1, then such a patient is likely to have a high risk of preterm birth and requires in-depth examination.

\section{Conclusion}

The developed mathematical model for assessing the risk of preterm birth in IDPs women has an informative value of $88.2 \%$ and can be used for primary screening.

The above formula allows us to identify a group of patients who need further in-depth diagnostic search and indications for preventive measures.

\section{References}

1. IDCP Global Overview 2015: People Internally Displaced by Conflict and Violence (2015) $\quad-\quad$ http://www.internal-displacement.org/sites/default/files/inlinefiles/20150506-global-overview-2015-en.pdf.

2. Internal displacement, available from: http://www.internaldisplacement.org/internal-displacement (Accessed 28 April 2020).

3. Biaggi A., Conroy S., Pawlby S. et al. Identifying the women at risk of antenatal anxiety and depression: A systematic review. J Affect Disord. 2016 Feb;191:62-77. doi: 10.1016/j.jad.2015.11.014.

4. Makhashvili N., Chikovani I., McKee M. et al. Mental disorders and their association with disability among internally displaced persons and returnees in Georgia. $\mathbf{J}$ Trauma Stress, 2014 Oct;27(5):509-18. doi: 10.1002/jts.21949.

5. King NM, Chambers J, O'Donnell K et al. Anxiety, depression and saliva cortisol in women with a medical disorder during pregnancy. Arch Womens Ment Health. 2010 Aug;13(4):339-45. doi: 10.1007/s00737-009-0139-5.

6. Kicia M., Skurzak A., Wiktor K. et al. Anxiety and stress in miscarriage. Pol J Public Health. 2015;125(3): 162-165. doi: https://doi.org/10.1515/pjph-2015-0046.

7. Ahmed S.R., El-Sammani Mel-K., Al-Sheeha M.A. et al. Pregnancy outcome in women with threatened miscarriage: a year study. Mater Sociomed. 2012;24(1):26-8. doi: 10.5455/msm.2012.24.26-28.

8. Parker V.J., Douglas A.J. Stress in early pregnancy: maternal neuro-endocrineimmune responses and effects. J Reprod Immunol. 2010;85:86-92. doi: 10.1016 / j.jri.2009.10.011. 
9. Weiss J.L., Malone F.D., Vidaver J. et al. Threatened abortion: A risk factor for poor pregnancy outcome, a population-based screening study. Am J Obstet Gynecol. 2004;190:745-50. doi: 10.1016 / j.ajog.2003.09.023.

10. Dadkhah F., Kashanian M., Eliasi G. A comparison between the pregnancy outcome in women both with or without threatened abortion. Early Hum Dev. 2010;86:19396. doi: 10.1016 / j.earlhumdev.2010.02.005. 